\title{
¿Está el catalán de Mallorca amenazado?
}

\section{Is the Catalan of Mallorca Threatened?}

\author{
LiAnA HotaŘová [liana.hotarova@tul.cz] \\ Technická univerzita v Liberci, República Checa
}

\begin{abstract}
RESUMEN
Un breve contexto histórico y político presentados en el siguiente escrito servirán de marco para una reflexión acerca de una posible amenaza del catalán en la mayor de las Islas Baleares. La Comunidad del mismo nombre, comenzó a considerarse una comunidad bilingüe a partir de 1983, cuando el catalán fue proclamado lengua cooficial junto con el castellano. En todas las comunidades españolas, que en sus estatutos de autonomía afirman la cooficialidad de otra lengua, en los cuales se han promulgado leyes que definen su política lingüística, concretando el uso de las dos lenguas en la administración pública, en la enseñanza y en los medios de comunicación, los resultados de su aplicación son muy distintos y se deben a diferentes motivos. El principal objetivo de este trabajo consiste en mostrar la complejidad de la realidad lingüística existente e identificar los motivos en torno a los cuales, actualmente giran los debates políticos, como son la realización de la política lingüística, la unidad de la lengua catalana y la denominación de la variedad local del catalán. Para completar el panorama del último motivo, se presentarán a continuación los resultados de tan solo dos preguntas de una investigación sociolingüística llevada a cabo por la misma autora.
\end{abstract}

\section{Palabras Clave}

Catalán; política lingüística; bilingüe; entrevista; variable sociolingüística

\begin{abstract}
This paper offers a brief historical and political context serving as a framework for a reflection on a possible threat for the Catalan language in the largest island of the Balearic Islands. The Community of the same name has been considered a bilingual community since 1983, i.e. year when Catalan was proclaimed a coofficial language along with Spanish. In those of the Spanish Communities whose statutes of autonomy determine the co-officiality of another language, laws defining their linguistic policy regarding the use of the two languages in public administration, in teaching and in the media have been enacted. Despite the same character of the laws, the results of their application differ significantly and also have various reasons. In this respect, the main objective of this work is to show the complexity of the current linguistic reality as well as to identify the reasons the political debates revolve around at present, such as the realization of the linguistic policy, the unity of the Catalan language and the denomination of the local variety of Catalan. To complete the panorama of the last aspect, the results two chosen questions of a sociolinguistic investigation carried out by the paper's author are presented below.
\end{abstract}




\section{KEYWORDS}

Catalan; linguistic policy; bilingual; interview; sociolinguistic variable

RECIBIDO 2019-10-31; ACEPTADO 2020-02-28

\section{Introducción}

La situación lingüística de la Comunidad Autónoma de las Islas Baleares es bastante peculiar y se debe a diversos factores históricos y políticos. El territorio del archipiélago, que posee una extensión total de $4.992 \mathrm{~km}^{2}$, se compone de las islas de Mallorca, Menorca, Ibiza, Formentera y otros islotes adyacentes. Es una de las comunidades autónomas en la que conviven dos lenguas oficiales a partir de 1983, año en el cual, se proclama en el Estatuto de Autonomía el catalán como lengua cooficial junto con el castellano. El estatus oficial para el catalán siempre depende de la legislación de cada comunidad, así como de la actitud de los respectivos gobiernos autonómicos en cuanto a la política lingüística. Asimismo, las actitudes de los hablantes hacia las dos lenguas oficiales no son uniformes, sino que varían de acuerdo con la edad, sexo, educación, país de origen y del entorno familiar.

A pesar de que, el Estatuto de Autonomía de esta Comunidad se refiere a las modalidades de la lengua catalana como a "modalidades insulares del catalán de Mallorca, Menorca, Ibiza y Formentera”, no todos sus hablantes están de acuerdo con esta denominación. Se han dado casos de denominar a la lengua catalana en un momento de cierta manera. Sin embargo, en otra situación, esta misma lengua ya recibe un nombre diferente. La denominación de la lengua cooficial no solo varía con respecto a las situaciones, sino también con respecto a los hablantes. Para una mejor ilustración de la opinión de los propios hablantes, se presentan a continuación los resultados de dos de las preguntas de una encuesta sociolingüística mucho más amplia llevada a cabo por la autora de este escrito en la isla de Mallorca. Las respuestas de los 101 entrevistados giran en torno a las preguntas “¿Qué lengua o dialecto hablan los mallorquines?”, y “El mallorquín es...”. De los resultados de la encuesta, se tenían en cuenta 4 variables: procedencia, sexo, edad y nivel sociocultural.

La realización de la política lingüística y la denominación de la variedad vernácula del catalán, son dos cuestiones muy importantes por considerar, en torno a los cuales, actualmente, giran los debates políticos. La realización de la política lingüística en las Baleares nunca ha estado exenta de problemas, según los objetivos y las preferencias del gobierno en el poder. La tercera cuestión, y no menos importe, es la puesta en duda de la unidad de la lengua catalana; a partir de ésta, se ha desarrollado una polémica al respecto que no ha cesado hasta nuestros días. Por una parte, están los que defienden la idea de que el catalán estándar y la variedad vernácula del catalán son una misma lengua. Por otro lado, la actitud secesionista, manifiesta una postura contraria afirmando que no se trata de una misma lengua. Así pues, igual que difieren las opiniones políticas, se diferencian las actitudes de los hablantes hacia las dos lenguas oficiales.

La sociedad mallorquina, que fue una sociedad social, cultural, económica y lingüísticamente aislada, a partir de los años 60 del siglo XX, se convierte en receptora de inmigración como consecuencia de la necesidad de mano de obra provocada por el turismo. Hasta esta época, los 
mallorquines no estaban en contacto cotidiano con personas de fuera. A partir de los años 90, la inmigración, que fue exclusivamente española, se amplió por personas procedentes de África, América Latina y de muchos países europeos.

La población inmigrante de aquella época, que ya supuso una cuarta parte de la población, veía el castellano como primera lengua a pesar del intento de incorporar el catalán en determinados sectores. Además, la gran mayoría de ellos se instalaban en Palma, donde entraban en contacto con el castellano. Así pues, no sorprende que el contacto con el catalán fuera mínimo. Los inmigrantes no sentían ninguna necesidad, salvo algunos casos, de aprender el catalán. Muchos de ellos, incluso, desconocían la existencia del catalán antes de la llegada a las islas. Sumando el hecho de que, a los catalanohablantes les resulta natural dirigirse a un desconocido en castellano, no soprende que la nueva población no necesite el catalán como lengua de integración. Además, también los latinoamericanos tienen el castellano como la lengua materna.

Así pues, hay que tener en cuenta la estructura de la sociedad mallorquina actual, formada por una parte importante de inmigrantes y forasteros, que en su mayoría no reciben formación lingüística en catalán; un grado de fluidez en el uso del castellano por la mayoría de los mallorquines jóvenes y de mediana edad, y, por último, se debe tomar en consideración la evolución demográfica. Todos estos factores ponen el catalán en una situación difícil.

\section{La situación de la lengua catalana no solo en Mallorca}

La Comunidad de las Islas Baleares es una de las comunidades autónomas cuyo gobierno decidió tomar provecho de la posibilidad de formar parte del dominio lingüístico catalán. El catalán, lengua derivada del latín vulgar, fue reconocido por la Constitución Española en 1978 como otra lengua oficial en las respectivas Comunidades Autónomas y se habla en un territorio

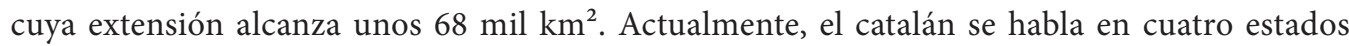
europeos (Andorra, España, Francia e Italia) y comprende dos bloques dialectales: oriental y occidental. Debido a la diversidad de realidades históricas y políticas, el conocimiento y el dominio del catalán, así como su desarrollo, no es uniforme ni homogéneo, sino que presenta variaciones según el territorio y las exigencias de las estructuras políticas. También el estatus oficial para el catalán dentro del mismo estado español no es igual y depende de la legislación de cada comunidad autónoma.

El momento decisivo para el catalán en las Islas Baleares fue la expansión de la corona catalanoaragonesa, cuando Jaime I, apodado "El Conquistador", ocupó la mayor de las islas en 1229, siendo ocupadas más tarde las de Menorca e Ibiza. Se creó un nuevo reino con su estructura administrativa y el catalán pasó a ser la lengua propia de las Islas Baleares, pasando ésta por varios períodos de esplendor y de persecución. Uno de los principales contribuidores a la formación de la lengua catalana literaria fue, sin duda, un gran filósofo y humanista mallorquín, Ramón Llull (1231-1315). Es autor prolífico de más de 250 obras, la mayoría de ellas escritas en catalán y en otras lenguas (latín, árabe u occitano).

Hasta el siglo XV, el catalán fue considerado, en territorios catalanes, una lengua de creación artística y de gobierno. Debido a la promulgación de los Decretos de Nueva Planta por Felipe V de España en el siglo XVIII, se abolieron las instituciones de autogobierno y se produjo una grave 
crisis de la literatura catalana. El catalán, de manera progresiva, perdió el carácter de lengua cooficial y el castellano pasó a ser la lengua de poder y de prestigio, ya que se transmitía a través de la escuela y los usos administrativos, quedando limitada a una parte reducida de la población. Para los miembros de las clases nobles isleñas que, a diferencia del resto de la población, poseían poder económico, político y cultural, por lo que la lengua del Estado fue asumida como un símbolo de estatus y de diferenciación respecto a las capas populares. Las clases medias mantuvieron el catalán oral y castellanizado (Ninyoles 1981).

Por lo que a la sociedad mallorquina del s. XIX se refiere, se caracteriza por ser una población rural mayoritariamente analfabeta. Según señala Herreras (2006: 47), el índice de analfabetismo de la población de aquella época, en algunos lugares, llegaba a superar el 90 \%. Y como la escuela era el único lugar donde los isleños podían aprender el castellano, no sorprende que esta situación afectara solo a las grandes ciudades, ya que las personas de pueblo seguían sin hablar ni entender el castellano.

La población mallorquina catalanoparlante monolingüe se caracteriza por ser conservadora y estar aislada por completo de las corrientes intelectuales de la Europa continental, aunque podemos encontrar un caso diferente en la isla de Menorca. La segunda en extensión y la tercera en población del archipiélago balear había estado bajo dominio británico durante casi todo el siglo XVIII. La isla pasó por tres períodos durante este dominio, incluyendo una breve ocupación francesa, ya que representaba para Gran Bretaña un valioso enclave en el Mediterráneo. Sus testimonios quedan en las costumbres de los menorquines, en la arquitectura y en el ámbito lingüístico. Hasta hoy en día podemos encontrar huellas del inglés en el léxico catalán de Menorca. Allí, el catalán es reemplazado por el castellano a principios del siglo XIX, sin embargo, antes ya se había experimentado esta situación con el francés en los ámbitos oficiales ${ }^{1}$.

Así pues, el empleo del castellano solo quedaba limitado a los empleados de la administración y a los estratos nobles isleños. En las zonas rurales tanto de Baleares, como de Cataluña y la parte catalanoparlante de Valencia, aparte del latín, que llegaba a través de la práctica religiosa, la única lengua usada fue el catalán. Asimismo, la Renaixença, un movimiento cultural y literario de la lengua catalana importante, fue limitado a unos círculos intelectuales muy reducidos. Hasta finales del siglo XIX y principios del XX, solo una pequeña parte de la sociedad estaba en contacto con otras lenguas que no fueran el catalán. La población balear se expresaba oralmente en catalán dentro de su vida cotidiana, la expresión escrita era en castellano.

La presencia de castellanohablantes en los pueblos antes de los años 50 del siglo XX era casi nula, con excepción de funcionarios o maestros de la escuela. En Palma, por otro lado, entre los burgueses progresistas y funcionarios ya había un cierto elemento castellanohablante. Sin embargo, y como podemos deducir fácilmente de las conversaciones del personaje central de Mort de dama de Llorenç Villalonga (Palma, 1897-1980), la aristocracia mallorquina de la ciudad utilizaba exclusivamente el catalán.

Con la dictadura franquista (1939-1975) se aceleró el proceso de castellanización de todo el territorio catalán. Debido a que España se convierte en un destino turístico a mediados del siglo $\mathrm{XX}$, se producen cambios importantes. Con la expansión del turismo, que sigue siendo la principal actividad económica, los ciudadanos baleares entran en contacto con diferentes lenguas,

1 Los territorios catalanes habían sido cedidos a la corona francesa a partir de 1659. 
costumbres y representaciones sociales de personas procedentes de fuera. Acabada la dictadura franquista, también comienza una expansión masiva de los medios de comunicación, la televisión y la radio. De este modo, el castellano penetra hasta en las familias autóctonas.

En 1983, es la primera vez que el catalán queda reconocido como lengua cooficial junto con el castellano en la Comunidad Autónoma de las Islas Baleares en el Artículo 3 del Estatuto de Autonomía. Según esta ley "todos los ciudadanos tienen el derecho de conocer las dos lenguas y usarlas, sin que nadie pueda ser discriminado por causa del idioma”. En el artículo 35 de la Ley Orgánica de reforma del Estatuto de Autonomía ya se especifica el término catalán, aludiendo de este modo a las diferentes modalidades como a "modalidades insulares del catalán de Mallorca, Menorca, Ibiza y Formentera".

Después de la aprobación del Estatuto de Autonomía, el catalán se incorpora en el sistema escolar y los niños comienzan a estudiarlo, más tarde en catalán. En esta época, el conocimiento de las dos lenguas oficiales ofrece la ventaja de acceder a determinados puestos de trabajo de la Administración regional y local. A pesar de la recuperación de la oficialidad del catalán, el castellano seguía siendo la lengua de reconocimiento prioritario, de la industria turística y de la justicia. La población inmigrante, que en aquella época ya supone una cuarta parte de la población, no tenía muchas posibilidades para entrar en contacto con el catalán y la única vía de adquisición de esta lengua fue la residencia en un entorno de población autóctona. Sin embargo, una buena parte de estos inmigrantes se instalaban en Palma, rodeados de la lengua castellana, así pues el contacto con el catalán fue mínimo. Además, lo normal para ellos es reconocer el castellano como primera lengua, y a pesar del intento de incorporar el catalán en determinados sectores, este perfil lingüístico sigue muy arraigado. No hay que olvidarse del hecho de que también los latinoamericanos tienen el castellano como lengua materna.

El estatuto significó para muchos mallorquines una nueva realidad sociolingüística que no dejaba de inquietar a los tradicionalistas mallorquines. Hasta esta época, si un catalanohablante de las Baleares estaba de acuerdo con el término catalán aplicado a su variedad o si veía en el catalán estándar el registro escrito común a los catalanohablantes de Baleares, de Valencia o de Cataluña, o si lo consideraba una simple imposición de una lengua que no sentía como propia, solo se trataba de predilecciones individuales, privadas. Sin embargo, esta situación cambió en el momento en el que la la lengua catalana fue declarada "propia" de Baleares y el catalán estándar escrito según las normas del IEC, se convirtió en oficial de la comunicación escrita del estado y de sus órganos autonómicos (Radatz 2007: 34). Algunos de los ciudadanos mallorquines empezaron a ver el catalán de manera muy crítica, incluso se oponían a la clasificación de su sistema lingüístico como al catalán.

La denominación del catalán por parte de sus hablantes no es uniforme. Se han dado casos de denominar a la variedad de la lengua catalana en un momento de una determinada manera para, a continuación, volver a referirse a la misma lengua, esta vez con un nombre diferente. Hay quienes se oponen a esta denominación y prefieren aplicar la nominalización popular referida a cada una de las variedades isleñas: mallorquín, menorquín, ibicenco, balear o catalán baleárico. Algunos mallorquines rechazan la clasificación de su sistema lingüístico como catalán, ya que no quieren que se los relacione con los catalanes. Para muchos de ellos es de Cataluña de donde provienen los principales movimientos de cambio (Garí 2014). Otros favorecen el uso de la lengua del estado y se ponen de acuerdo en que el catalán quede postergado a funciones folclóricas. 
Según Garí (2002), los primeros prejuicios lingüísticos aparecen ya en el siglo XVIII, cuando el catalán empieza a ser arrinconado en los ámbitos y usos formales, y se diluye la unidad administrativa y política de los territorios catalanes. Sin embargo, no será hasta este siglo, cuando los ataques a la identidad de la lengua vuelvan a ser más intensos. Y a pesar de que en los años ochenta se recuperaron los antiguos ámbitos de uso de la lengua catalana en la escuela, instituciones, prensa, radio o televisión, algunos sectores se mostraban en contra y negaron la identidad catalana de la lengua hablada en Mallorca (Garí 2002).

La actitud secesionista considera el catalán de Mallorca como lengua distinta del catalán. Hay varias instituciones y fundaciones: Cívico-cultural españolista o Círculo Balear (1999). En octubre de 2013, aparece otra institución más, la de Jaume III, cuyo objetivo es defender las modalidades lingüísticas insulares, ya que "con la estandarización de la lengua se pierden palabras mallorquinas, siendo sustituidas por las catalanas“2

En 2005, La Academia de la Lengua Balear, presentó una gramática propia. Esta nueva Gramàtica Normativa d'es Baléà se distancia de la gramática oficial catalana, oponiendo la forma castellana con la catalana, presentando la forma balear con una ortografía particular. Garau Rosselló, uno de los miembros más destacados de La Academia, que carece de reconocimiento oficial, es autor de libros y gramáticas, y advierte (2012: 5):

Hoy día se da el caso que, debido al afán codicioso de sectores políticos denominados nacionalistas, encaramados en lo más alto de la dirección de sus países, llevan a cabo políticas de extinción o cuando menos de sustitución cultural y lingüística, sobre las comunidades de hablantes cuya lengua materna es distinta a la suya. Siendo ese el caso del idioma balear, forma natural y vernácula del pueblo balear desde hace más de dos mil años, que, por intereses político-económicos está siendo sustituido por el catalán, lengua que cuenta en Baleares con tan sólo 30 años de implantación, pero que en 1983 y sin consultar al pueblo, fue nombrada lengua oficial juntamente con el español...

\section{La estructura de la población}

La época de cambio decisivo en la estructura de la población mallorquina se presenta en la década de los 50 y 60 del siglo pasado. Es precisamente a partir de estos años, cuando unas tierras que tradicionalmente habían producido emigración sin parar, se convierten en receptoras de inmigración.

La emigración de mallorquines, menorquines e ibicencos fue una de las características fundamentales de la dinámica de la población balear y se producía continuamente en los años de escasa cosecha. Las estructuras sociales eran viejas y la gente que trabajaba de sol a sol muchas veces sufría de hambre. La emigración se intensificó a finales de la década de los ochenta del siglo XIX con la crisis. A pesar de la reducción de la mortalidad y de la permanencia del índice elevado de natalidad, no se produce un incremento de puestos de trabajo. Entre 1887 y 1900, cada año

2 Fundación Jaime III <http://www.jaumetercer.com/index.php/multimedia/player/general/presentaci\%C3\%B3fundaci $\%$ C3\%B3-jaume-iii> 
abandonan las Baleares unas dos mil personas, que deciden asentarse en varios países latinoamericanos, en la Península y en el sur de Francia. Esta emigración se prolonga durante las primeras décadas del siglo XX.

A mediados del siglo XX, unas tierras que tradicionalmente habían producido emigración, se convierten en núcleo receptor de inmigración. Debido a la recuperación económica europea y el Plan de Estabilización español, en plena dictadura de Franco, se inicia la etapa de turismo de masas. Las actividades turísticas provocan un incremento de los puestos de trabajo, y las islas, que durante mucho tiempo se habían mantenido en un crecimiento inferior a la media de estado español, empiezan a superarla. La necesidad de una gran cantidad de mano de obra barata dio lugar a un importante movimiento demográfico que hizo llegar miles de peninsulares castellanohablantes, en su mayoría de Andalucía. La inmigración fue exclusivamente española hasta la década de los noventa, ya que luego se amplió por una nueva inmigración procedente de varios países europeos, de América Latina y África central. El turismo y la construcción han causado un crecimiento de la capital, Palma, llamada popularmente Ciudad, y la aparición de urbanizaciones en lugares turísticos.

El turismo empieza a convertirse en un producto industrial, y la sociedad mallorquina comienza a experimentar una modernización a causa de grandes movimientos demográficos. Los inmigrantes se instalaban mayoritariamente en Mallorca e Ibiza, y, debido a que es allí donde también nacen sus hijos, aumenta la tasa de natalidad y la población rejuvenece. Es precisamente a partir de esta época, cuando la población activa de las islas deja de ser mayoritariamente agraria y empieza a ocuparse casi en exclusiva del turismo. Los datos expuestos a continuación, corresponden al padrón de habitantes de Ibestat (Instituto de Estadística de las Baleares). Mientras que en 1860 las islas contaban con unos 269 mil habitantes, ${ }^{3}$ cien años más tarde, en 1960, esta cifra sube a unas 443 mil personas. Esta cantidad de personas, en tan solo diez años, supera los 558 mil habitantes. Por lo que respecta a los inmigrantes peninsulares, entre 1955 y 1975 ya se registran 82 mil, presentando así un 26 \% de la población (Hernández-Marimon 1998: 194). El incremento de la población, condicionado por el turismo y por los servicios relacionados, no han seguido un mismo ritmo, ni siquiera la distribución de inmigrantes fue la misma en todos los municipios.

La población extranjera que residía en Mallorca no representaba una cantidad importante hasta los años noventa del siglo XX. Esta situación cambió considerablemente con el comienzo de una fuerte corriente de turismo de residentes alemanes. Los jubilados alemanes, que establecieron su residencia permanente, sobre todo, en Mallorca e Ibiza, buscaban un lugar con condiciones climáticas y económicas favorables. Esta inmigración, al mismo tiempo, generaba la población de edad laboral que prestaba sus servicios a esta población (médicos, comerciantes o gestores inmobiliarios). El asentamiento de la población alemana en Mallorca, aumenta las posibilidades de conexión aérea entre varias ciudades alemanas y la isla, así como la cantidad de agencias inmobiliarias que ofrecen viviendas. Incluso se desarrollan medios de comunicación locales en la lengua alemana, ya sea radio o televisión.

Dicho anteriormente, hasta la etapa de inmigración, los ciudadanos mallorquines no tenían contacto cotidiano con personas de fuera. Esta situación cambia a partir de los años sesenta del

$3<$ https://ibestat.caib.es/ibestat/estadistiques/97524e3c-205b-4c86-b4f5-7bf9774651f9/8a897a13-78ac-43ee-9dba8ddcf96df567/es/I101001_8603.px> 
siglo pasado, cuando Mallorca se convierte en núcleo receptor de inmigración como consecuencia de la necesidad de mano de obra que provoca el turismo. Debido a varias olas de turismo e inmigración, han llegado de este modo a las Islas personas de África (central y Marruecos), América Latina y de muchos países europeos (Alemania, Italia, Reino Unido, Rumanía), y es precisamente a partir de este momento, cuando el panorama lingüístico se vuelve tan diverso y complejo. Esta gran heterogeneidad cultural dio lugar a muchas situaciones y contextos lingüísticos.

\section{El contexto político}

La lengua catalana, después de su aprobación como lengua cooficial de esta Comunidad en 1983, ha vivido una desventaja social en relación al castellano. Para fomentar y normalizar su uso en todos los medios de comunicación social, fue creada la Ley de Normalización Lingüística (3/1986) que implica que:

Todos tienen el derecho de poder dirigirse en catalán, oralmente o por escrito, a la Administración, a los organismos públicos y a las empresas públicas y privadas. También, implica poder expresarse en catalán en cualquier reunión y desarrollar en esta lengua las actividades profesionales, laborales, políticas, sindicales, religiosas y artísticas; así como recibir la enseñanza en catalán y también la información en todos los medios de comunicación social.

Su objetivo consistía en hacer efectivo el uso normal y progresivo de la lengua catalana en el ámbito oficial y administrativo, siempre regulado por el Gobierno de la Comunidad Autónoma de las Islas Baleares (CAIB). Actualmente, existen varias instituciones que se ocupan de controlar la normalización de la lengua catalana. Las formas correctas del catalán las determina la sección filológica de la Universidad de las Islas Baleares.

La realización de la política lingüística en el archipiélago balear no es uniforme, sino que depende de las preferencias y los intereses de los miembros del gobierno gobernante (PP o PSOE).

Con el Decreto 100/1990 se regula el uso de las lenguas oficiales en las actividades administrativas. Durante el primer gobierno de Jaume Matas (1996-1999), se promulgó el Decreto de mínimos que implantaba la lengua catalana como vehicular en la enseñanza no universitaria como mínimo en un 50 \% de la actividad escolar. Durante su segundo gobierno, (2003-2007), Matas inició un giro españolizador con un decreto que permitía a los padres elegir la lengua de educación de sus hijos. Esta Ley volvió a ser repuesta con el representante del españolismo, José Ramón Bauzá.

Los dos gobiernos del socialista Francesc Antich (1999-2003 y 2007-2011), con la Ley de comercio y la Ley de salud, seguían con la promoción del catalán. La Ley 11/2001, sobre la ordenación de la actividad comercial en las Islas Baleares, en el artículo 8, cubrió los derechos lingüísticos de los consumidores cuando, en los establecimientos que disponen de una plantilla laboral de más de tres trabajadores, los consumidores tienen, además, el derecho de ser atendidos en la lengua oficial de las Islas Baleares que prefirieran. La señalización, los carteles de información general de carácter fijo y los documentos de oferta de servicios para los consumidores de los establecimientos abiertos al público pasaron a ser redactados, como mínimo, en catalán. 
El 9 de diciembre de 2013 fue aprobada la Ley orgánica (8/2013) para la mejora de la calidad educativa (LOMCE). Esta nueva ley, propuesta por el ministro de Educación José Ignacio Wert, presenta aspectos novedosos relacionados con las lenguas cooficiales. La ley hizo varias modificaciones en las materias troncales y en varias asignaturas, tanto de primaria como de secundaria. Por otro lado, también indica que las comunidades con lengua cooficial tendrán que asegurarse de que las administraciones educativas "garantizarán" el derecho a que los alumnos puedan recibir la enseñanza en la lengua oficial del Estado. Se establece que, incluso, se les podrá exigir pagar la escolarización en centros privados a todos aquellos alumnos cuyos padres deseen que sus hijos sean escolarizados en castellano cuando no haya oferta docente pública que cubra esta necesidad. También se hará efectivo el derecho de los alumnos a recibir conocimientos sin ser discriminados por razón de lengua. Esta Ley fue propuesta durante la última presidencia del PP por José Ramón Bauzá (2011-2015).

Con Bauzá al poder, se llevó a cabo una serie de reformas lingüísticas con el objetivo de abrir las puertas del mercado laboral a la población local reduciendo el catalán en la enseñanza mediante el Decreto de trilingüismo (TIL) ${ }^{4}$, a favor del castellano e inglés. La lengua catalana, protegida por la legislación lingüística autonómica, ya no es la única propia de la administración autonómica; ahora lo es también el español. Asimismo, se ha suprimido el requisito general de conocimiento de la lengua catalana para la función pública. Bauzá, en varias ocasiones, criticó la apuesta sobre la soberanía catalana y prefirió no formar parte de los Países Catalanes. De este modo, se han impulsado políticas de fragmentación de la lengua, cuando Bauzá afirmó que la lengua que se habla en Mallorca no era el catalán, sino el "mallorquín” (Carranza 2012). Se han demostrado casos de intentar usar el catalán de las Islas en los manuales escolares. El último presidente del Partido Popular se oponía a seguir colaborando con Cataluña, además de no hacer ninguna aportación económica. Incluso se conoce bastante su repetida desvinculación del Instituto Ramón Llull (IRL).

La actual presidenta de Baleares, Francina Armengol, del PSOE, ganadora de las elecciones en 2015, dio un gran giro a la política lingüística. Como la nueva presidenta no estaba de acuerdo con el modelo educativo trilingüe propuesto por el gobierno anterior en 2013, decidió desactivar todas sus leyes. Asimismo, advirtió de que seguiría el modelo lingüístico tradicional que se adaptó a partir de 1983 en la enseñanza pública y privada, además de proteger en las escuelas, el uso de la lengua propia de las Baleares según el Estatuto de Autonomía, el catalán.

\section{La investigación sociolingüística}

Para acercar al lector la situación desde el punto de vista de personas residentes en Mallorca, decidimos presentar dos preguntas de una investigación cuantitativa realizada por la autora de este escrito, cuyo objetivo era determinar las actitudes de los hablantes de la isla de Mallorca hacia las lenguas cooficiales, partiendo de una encuesta. Para este objetivo, se aprovecharon dos instrumentos diferentes: un cuestionario de respuestas abiertas y cerradas, y otro cuestionario

4 El trilingüismo en Baleares (TIL) fue un modelo de educación cuyo objetivo consistía en mejorar la capacitación del alumnado formándose en tres lenguas en los colegios e institutos. 
que empleaba la técnica del matched-guise, cuyos resultados no vamos a presentar. Ya que éramos conscientes de que varios factores influían en las actitudes de los hablantes, se han determinado cuatro variables: procedencia, sexo, edad y nivel cultural. En total hemos podido entrevistar a 101 personas procedentes de dos lugares previamente escogidos: la capital de Palma de Mallorca y el pueblo de Porreras, de unos 5 mil habitantes, de tres generaciones distintas y de tres niveles sociales, contando con dos factores decisivos: la ocupación y el nivel de instrucción. Los participantes se reclutaban por medio de un muestreo denominado "bola de nieve", ya que los informantes recomiendan o proponen a otros informantes, componiendo de esta manera una red de personas.

Una de las dos preguntas cuyos resultados decidimos presentar en el siguiente escrito trataba de verificar el término con el que los hablantes se referían a la lengua hablada en la isla de Mallorca. Otra de las preguntas tenía la intención de ver la opinión de los encuestados sobre la clasificación del catalán.

Así pues, la primera pregunta “¿Qué lengua o dialecto hablan los mallorquines?” no le ofrecía al entrevistado ninguna respuesta, para que él pudiera contestar como mejor le parecía, sin haber sido manipulado ni encaminado. La pregunta se podría haber formulado de diferente manera, pero teniendo presente la disputa actual, tratamos de evitar cualquier tipo de discusión al iniciarse la entrevista.

Nos ha parecido interesante presentar aquí el gráfico de la variable procedencia, ya que podemos observar una clara preferencia de los habitantes de Mallorca por el término mallorquín; los de Palma muestran la misma preferencia en un $59 \%$; los de Porreras en un $57 \%$ de los entrevistados. Como podemos ver en este mismo gráfico, se da también el caso de participantes que optan por el término catalán tanto en Palma (un 15 \%) como en Porreras (un 28 \%). Llama la atención la predilección de algunos de los informantes hacia el catalán-mallorquín. Como se puede ver en el gráfico, están los que consideran el castellano como la única lengua hablada en la zona y una única persona ha aplicado el término balear.

Por lo que se refiere a la variable edad, la mayoría de los encuestados de las tres generaciones sentían preferencia por la denominación mallorquín (la primera generación en un $54,5 \%$, la segunda en un $60 \%$ y la tercera generación en un 58,3\%). Sorprende una similar distribución entre las tres generaciones por el término catalán (22,7 \%, 20 \% y 20,8 \%). Otra información que ha aportado esta variable es que las personas que habían señalado que los mallorquines hablaban castellano eran de primera generación.

También la variable nivel sociocultural demostró la preferencia de la gente de nivel sociocultural medio (N2) y bajo (N3) por el término mallorquín (un 55,6 \% y un 85,7 \%, respectivamente), mientras que la gente de nivel alto (N1) opta por el vocablo catalán en un 42,1 \%.

La segunda pregunta de interés fue "El mallorquín es ..." y ofrecía algunas posibilidades de cómo responder:
a) un dialecto del catalán
b) una lengua diferente y diferenciada del catalán
c) la misma lengua que se habla en Cataluña (Barcelona) 


\section{Pregunta 1}

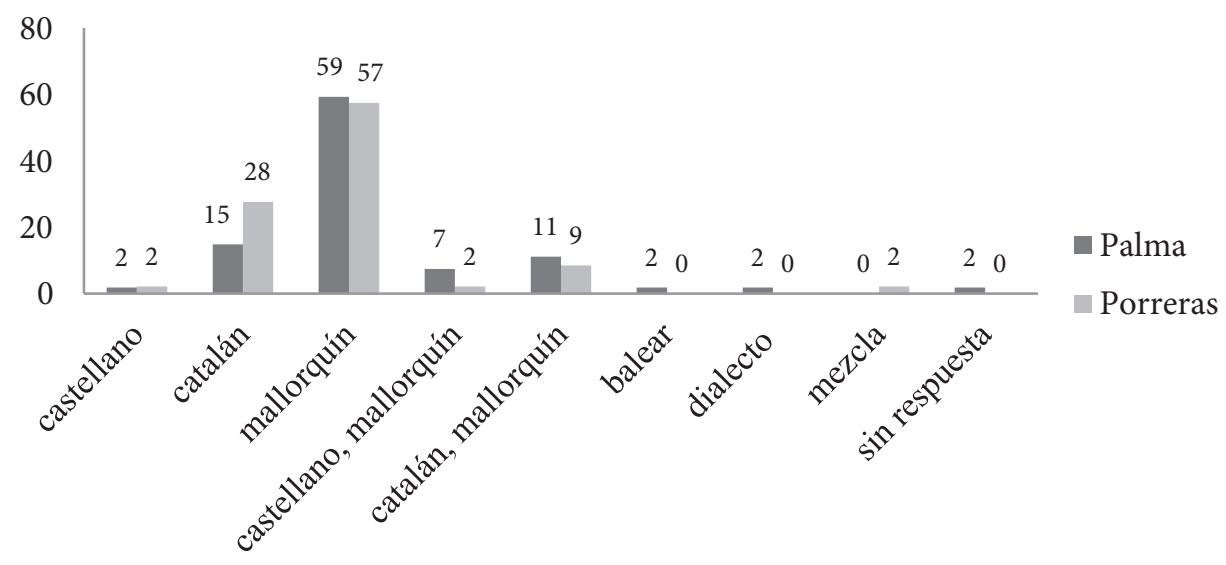

Gráfico: Resultados de la variable «procedencia»

De los resultados se desprende que el mallorquín ${ }^{5}$ es un dialecto del catalán, respondiendo de este modo un 59,3 \% de los informantes de Palma y un 70,2 \% de los de Porreras. Algunos informantes consideraban el mallorquín una lengua diferente, sobre todo en Palma (un 27,8 \%), mientras que los de Porreras solo un 17 \%. Fueron muchas las razones dadas para llegar a este rechazo de relacionar el mallorquín con el catalán. Una explicación bastante común por parte de los entrevistados fue: los catalanes llegaron a ocupar la isla y les quitaron la lengua a los mallorquines, llevándose el ejemplo para codificar más tarde el catalán por Pompeu Fabra. Y como último, cabe resaltar que una persona de Palma y dos de Porreras contestaron que el mallorquín es un dialecto del catalán y la misma lengua que se habla en Cataluña.

En lo que se refiere a los resultados que se desprenden de la variable sexo, estos datos ponen en evidencia que las mujeres, con un 69,7 \%, consideran en su mayoría el mallorquín un dialecto del catalán y los hombres, en un 54,3\%. Son 11 los hombres y 12 las mujeres que manifiestan no considerar el mallorquín y el catalán una misma lengua.

Para la mayoría de las personas que configuran la primera generación, el mallorquín es un dialecto del catalán. Solamente entre los encuestados de la segunda generación (un 16,4 \%) aparecen participantes que consideran el mallorquín como la misma lengua que se habla en Cataluña.

La mayoría de los entrevistados de los tres niveles socioculturales consideran el mallorquín un dialecto del catalán. Como esperábamos al iniciar la entrevista, son precisamente los entrevistados de nivel bajo (un 35,7 \%) los que consideran el catalán peninsular y el isleño una lengua diferente. Por otro lado, nos ha sorprendido que los encuestados de nivel alto señalen también el mallorquín una lengua diferente, correspondiendo con un 15,8 \%. Solo entre los de nivel alto y medio encontramos participantes, un $11 \%$ del total, que han respondido que se trata de la misma lengua que se habla en Cataluña.

5 Con este término nos referiremos a la modalidad del catalán de Mallorca. 


\section{Las percepciones lingüísticas}

Como es de suponer, la convivencia de culturas y lenguas de orígenes diferentes, a parte de la coexistencia de dos lenguas con la misma validez legal en un mismo territorio, puede presentar algunos problemas.

Por lo que respecta a la mayor de las islas, hasta mediados del siglo XX, los lingüistas (Ballerman-Melià 2010: 273; Bibiloni 2015: 121) se refieren a esta etapa como a la de diglosia, cuando la población mallorquina en su vida ordinaria se expresaba en catalán, mientras que en los usos oficiales y escritos en castellano. Más tarde, el conocimiento del castellano ya se había extendido debido a la escolarización obligatoria y a la industria turística, mientras que la lengua catalana no estaba presente ni en la escuela, ni tenía la consideración oficial. No obstante, la mayor población de los pueblos mallorquines permanecía sin entrar en contacto con el castellano. En la población mallorquina, competente en castellano, la dificultad se notaba en la expresión, no en la comprensión.

La inmigración de entonces era española, con excepción de personas procedentes de Cataluña y de Valencia. Más tarde, por lo que respecta a los inmigrantes extranjeros, su integración se hacía de manera exclusiva a través del castellano. Los inmigrantes no tenían ninguna necesidad de aprender el catalán, sin embargo, (como señalan Ballerman-Garí, 2010: 275), incluso hoy en día es posible residir de manera temporal o permanente en las Islas Baleares sin tener conocimientos de esta lengua. La mayoría de ellos, entonces, permanecían monolingües, salvo algunos casos, que han aprendido el castellano. Según Melià-Mestre (2007), el 70 \% de los inmigrantes incluso desconocían la existencia del catalán antes de la llegada a las islas. La necesidad de aprender esta lengua como lengua de integración se debe también al comportamiento de los autóctonos, a los que les parece natural dirigirse a un desconocido o a un castellanohablante, en castellano. Actualmente, esta norma ya se puede dar por implantada (Bibiloni 2015).

Ballerman-Melià (2010: 280) señalan, que los inmigrantes extranjeros de Mallorca suelen presentar dos actitudes con relación a la cultura y la lengua catalana. La gran mayoría las percibe como un obstáculo, otros muestran un interés elevado de integrarse activamente entre la población autóctona. Los motivos para aprender el catalán son diversos: la necesidad de acceder a determinados puestos de trabajo, interés cultural, la convivencia con una pareja catalanoparlante, las experiencias vividas en Cataluña o la intención de tener una relación más intensa con la población autóctona.

Según un estudio realizado por Ballerman-Melià (2010) con veinte inmigrantes adultos residentes en Palma, uno de los aspectos que los entrevistados tienen en común es que la mayoría son personas formadas académicamente.

Por lo que se refiere al conocimiento del catalán, no constituye un deber para los recién llegados adultos. Ellos no reciben ningún tipo de formación lingüística obligatoria, como es el caso de los escolares. Para los adultos se ofrecen cursos de lengua programados por diferentes instituciones, debido a que la gran mayoría de inmigrantes se han instalado en Palma, viviendo en un entorno social de lengua castellana en casi todos los ámbitos sociales. La única manera para poner en práctica los conocimientos de catalán es la participación en actividades culturales.

Hay varias asociaciones y proyectos culturales y lingüísticos que se dedican a la integración de los inmigrantes y la promoción del catalán mediante actividades culturales de ocio. Una de ellas, 
OCB (Obra de Cultura Balear), es una asociación cultural no gubernamental que ofrece actividades culturales complementarias a los cursos lingüísticos. El proyecto “Todos juntos" se inició en 2008 y promueve actividades entre catalanohablantes e inmigrantes, para impulsar el uso social de la lengua catalana entre todos los participantes.

Los residentes procedentes de otras comunidades, en su mayoría, no hablan catalán. A cambio, los de Países Catalanes, de Valencia o de Mallorca, no todos, ya que de muchos de ellos, sus hijos y nietos son de inmigrantes españoles. Presentan una gran complejidad en cuanto a sus competencias y usos lingüísticos.

Teniendo en cuenta las observaciones previas, no sorprende que el perfil lingüístico de la población de Mallorca vaya desde el monolingüismo catalán en áreas rurales, siguiendo por el continuum del bilingüismo, incluso plurilingüismo, acabando en el monolingüismo castellano o de otra lengua extranjera (Melià Garí 2014).

Por un lado, actualmente, la mayoría de los mallorquines jóvenes y de mediana edad, han alcanzado un grado de fluidez en el uso de español. La influencia del español sobre el catalán se manifiesta, no solo en el léxico, sino también en la fonética, en la sintaxis y en las estructuras semánticas. Bibiloni (2015) llama la atención sobre un fenómeno generalizado en el terreno de la dicción que consiste en la adopción de modos articulatorios propios del español. El parlar bleda, según el autor, es un nuevo hablar que actualmente está implantado en el área metropolitana de Palma y avanza hacia la Parte Forana entre la gente menor de 30 años, que amanaza con la desfiguración de la dicción catalana tradicional. Y, esta españolización pone el catalán en una situación débil.

Por otro lado, hay que tener en cuenta que los forasteros ${ }^{6} \mathrm{y}$ los extranjeros ya representan una parte significante e importante de la población mallorquina. Debido a todos los factores anteriormente expuestos, el futuro del catalán es muy difícil de predecir.

\section{Valoraciones finales}

Como hemos podido comprobar a lo largo de este escrito, la situación lingüística de la mayor de las islas de la Comunidad de las Islas Baleares es bastante peculiar y llama atención la cantidad de factores que influyen en ella. La realización de la política lingüística a partir de los años 80 del siglo pasado, igual que la confusión terminológica y la puesta en duda de la unidad de la lengua catalana, son tres temas, en torno a los cuales giran debates políticos, que aún no han cesado.

La sociedad mallorquina, caracterizada hasta mediados del siglo XX por una población rural mayoritariamente analfabeta, entra en contacto con diferentes lenguas, costumbres y representaciones sociales de personas procedentes de la Península, América Latina, África y varios países europeos. Ya en plena dictadura franquista se inicia la etapa de turismo de masas y, como las actividades turísticas necesitaban una gran cantidad de mano de obra barata, se produce un importante movimiento demográfico. La inmigración fue exclusivamente española hasta la década de los noventa, cuando ésta se amplió por una nueva inmigración extranjera. El turismo y la construcción han causado un crecimiento de la capital y aparecieron urbanizaciones en lugares turísticos. 
Las islas Baleares, y sobre todo Mallorca, han experimentado una profunda transformación social, económica y demográfica que condicionan la situación en la que se encuentra el catalán. La persecución política que ha padecido esta lengua y la imposición legal del castellano durante más de dos siglos y medio, creó, en la población isleña una mentalidad diglósica. La población mallorquina en su vida ordinaria se expresaba en catalán, mientras que en los usos oficiales y escritos en castellano.

La convivencia de dos lenguas oficiales no es nada excepcional en el territorio español, ya que la mayoría de ellas son bilingües, e incluso se hablan más de dos lenguas. Lo que sí puede resultar de interés es, que, a pesar de que el Estatuto de Autonomía de las Islas Baleares (1983) se refiere a las modalidades del catalán como a "modalidades insulares del catalán de Mallorca, Menorca e Ibiza", los hablantes no están de acuerdo con esta denominación. La designación del catalán puede variar de acuerdo con la situación o al hablante. Para una mejor ilustración de esta afirmación hemos presentado las opiniones de 101 personas entrevistadas en una investigación sociolingüística llevada a cabo en la Isla de Mallorca por la autora de este escrito.

Según los resultados presentados, la mayoría de los entrevistados de las dos localidades (un 59 \% en Palma y un 57 \% en Porreras) solían referirse al instrumento lingüístico de los mallorquines en su mayoría con el término mallorquín.

Los resultados de la segunda pregunta ofrecían las respuestas sobre lo que es el mallorquín ... La más habitual de las respuestas que se ha ofrecido es que el mallorquín es un dialecto del catalán, respondiendo de este modo un 59,3 \% de los informantes de Palma y un 70,2 \% de los de Porreras. Nos ha sorprendido que un 27,8 \% de los encuestados de Palma y un 17 \% de Porreras consideran el mallorquín una lengua diferente del catalán. Si atendemos a la variable edad, podemos ver que los entrevistados de la tercera generación opinan, en un 29,2 \% de los casos, que el mallorquín y el catalán son lenguas diferentes, mientras que, entre las personas pertenecientes a la primera y segunda generación, estos porcentajes ascienden a un $22,7 \%$ y un $20 \%$, respectivamente.

Cuando se produjo la inmigración española, la gran mayoría de la población mallorquina ya era competente en castellano, considerada la lengua superior. Esta situación no ha cambiado a pesar de todos los cambios sociales favorables al catalán. También la integración de la nueva población se hacía a través del castellano, ya que el conocimiento del catalán no constituye para los inmigrantes un deber. No reciben formación lingüística obligatoria como en caso de los escolares. Solo para los interesados, se ofrecen cursos de lengua programados por diferentes instituciones y actividades culturales de ocio. Además, la evolución demográfica no ha cesado y la españolización de la mayoría de los mallorquines jóvenes y de mediana edad, que han alcanzado un grado de fluidez en el uso de español, pone el catalán en una situación débil.

\section{Referencias bibliográficas}

Ballerman, D.; \& Melià, J. (2010). La llengua catalana a les illes Balears i les percepcions del nouvinguts. Journal of Catalan Studies, 4, 269-295.

Bibiloni, G. (2015). Monogràfic sobre la llengua catalana: Mallorca. DivẼrsia, 7, 119-132. 
Carranza, E. (2012). Baleares abandona el Institut Ramon Llull. La Vanguardia, <http://www.lavanguardia. com/local/islasbaleares/20121108/54354281482/baleares-abandona-institut-ramon-llull.html>

Fundación Jaime III, <http://www.jaumetercer.com/index.php/multimedia/player/general/presentaci$\% \mathrm{C} 3 \% \mathrm{~B} 3$-fundaci\%C3\%B3-jaume-iii $>$

Garau Roselló, M. (2012). Balear: La lengua vernácula de Baleares. Sevilla: Publidisa.

Hernández, J. L.; \& Marimon, A. (1998). La llengua. In C. Blanes, \& A. Marimon, Història de Mallorca (vol. 3) (pp. 189-220). Palma: Editorial Moll.

Instituto de Estadística de las Islas Baleares: Resumen demográfico, Población de Mallorca, <http:// ibestat.caib.es/ibestat/estadistiques/c29176ea-c2c4-4d65-98c1-23d9c47df46a/768ef54f-c7a1-4d53-8041-96a8be116e2b/es/Res_00021p.px>

Melià, J. (2001). La política lingüística del Govern de les Illes Balears. Llengua i Ús: Revista tècnica de política lingüistica, 20, 4-11.

- (2002). La situació lingüística a les Illes Balears. Comentaris al voltant d’una enquesta. Llengua i Ús: Revista tècnica de política lingüística, 25, 61-64.

- (2014). La pertinença lingüística: el cas de les Illes Balears. Treballs de Sociolingüística Catalana, 24, 225-240.

Melià, J.; \& Mestre. L. (2007). Els alumnes dels cursos per a no catalanoparlanst adults. Coneixement, usos i prepresentacions socials de la llengua catalana, <http://www.uib.es/depart/dfc/gresib/curs/2007/meliamestre/index.html>

Ninyoles, R. Ll. (1981). Tendencias fundamentales de la política lingüística: opciones contextuales en el ámbito de la educación bilingüe. Revista de educación, 268, 15-30.

Radatz, H.-I. (2007). De la Mallorca preturística a la moderna: La desdialectalització del català de Mallorca. Els Marges, 81, 29-41. 
